\title{
チョウチンゴケ科数種の構造的性染色体 I.
}

\author{
小 野 莞 爾*
}

Kanji ONO*: Structural Sex-chromosomes in Some Species of Mniaceae I.

Received January 9, 1967

\begin{abstract}
Karyological studies were made on three dioecious species of Mniaceae from Japan with special reference to the structural sex-chromosomes. Mnium japonicum and $M$. cuspidatum var. trichomanes were found to have structural sex-chromosomes similar to those of $M$. maximowiczii previously reported ${ }^{1}$. The structural sexchromosomes $\mathrm{X}$ and $\mathrm{Y}$ of the three species are the longest heterochromosomes $(\mathrm{H})$ of the complement of each female gametophyte and male gametophyte. And, they are similar to each other in total length and in the position of constriction at metaphase of mitosis. The heteropycnotic part of $\mathrm{Y}$, on the other hand, was found to be larger than that of $X$. The karyotypes of three species studied can be
\end{abstract} formulated:

$$
\left\{\begin{array}{l}
\text { 우 } \mathrm{K}(\mathrm{n})=7=\mathrm{V}\left(\mathrm{H}_{1} \mathrm{X}\right)+\mathrm{V}\left(\mathrm{H}_{2}\right)^{n h}+2 \mathrm{v}+\mathrm{J}+\mathrm{j}+\mathrm{m}(\mathrm{h}) \\
\text { 今 } \mathrm{K}(\mathrm{n})=7=\mathrm{V}\left(\mathrm{H}_{1} \mathrm{Y}\right)+\mathrm{V}\left(\mathrm{H}_{2}\right)^{n h}+2 \mathrm{v}+\mathrm{J}+\mathrm{j}+\mathrm{m}(\mathrm{h})
\end{array}\right.
$$

辰野・瀬川11はさきにチョウチンゴケ科のッル チョウチンゴケ(Mnium maximowiczii) に構造的 性染色体 structural sex-chromosome 学見した。 これは, 従来動植物の性染色体が, 一般に雌雄の間 で数や大きさなどの形態的な差で見わけられてい たのとは異なり, 雌雄の染色体の内部の構造の差で 区別される新しい型の性染色体である。すなわす， ッルチョウチンゴケの場合は, 䧳雄の核板中最大 で，乙かもとくに多くの異質染色質它持つ異質染色 体 $(\mathrm{H})$ が，異質染色質の量と分布をたがいに異に するのである.その後瀬川2-5) 注構造的性染色体を 多くの苔類で発見している。しかし，蘚類におけ る構造的性染色体は，上記ツルチョウチンゴケの他 にはHypnum 属などのわずかに 8 種で報告されて いるにすぎない(失野6)）、筆者は蘚類における構造 的性染色体の例を増すため, その発見につとめてい るが，本報告では，上記ッルチョウチンゴケの詳細 な再観察と,そのほか新たに発見したナガバチョウ

* 広島大学理学部植物学教室 Botanical Institute, Faculty of Science, Hiroshima University, Hiroshima, Japan.
チンゴケ (M.japonicum), コツボゴケ (M. cuspidatum var. trichomanes) の 2 種の構造的性染 色体について報告する.

観察方法ならびに核型表示法はさきの辰野・小 野7)の場合と同様である.

\section{観 察 結 果}

\section{ツルチョウチンゴケ (Mnium maximowiczii)}

本種ほ広島市付近産のもので観察した。 本種の染色体数は, さきに下斗米・小山 ${ }^{8)}$, 辰野 9 , 辰野・矢野 ${ }^{10)}$, 辰野・瀬川11括よび辰野・小野7)が 報告しているごとく, 此雄ともに $\mathrm{n}=7$ である (Figs. 3，6，18，21). さきに辰野・小野7) は，本種 の此件株の 7 個の染色体を, 中期の relative length, form percent $(\mathrm{F} \%)$ 加, 形態的に A, B, C, $\mathrm{D}, \mathrm{E}, \mathrm{F}, \mathrm{m}$ に区別した。本研究では, さらに雌 株と雄株の染色体をあわせて観察し, これを詳細に 比較した，その結果，少くとも中期においては，此 雄の染色体間に，形および大きさの区別は認められ ない (Figs. 3, 6, 18, 21; Table 1).

$\mathrm{A}$ 染色体は, 䧳雄ともに中期核板中最長で, 長 
さは $6.4 〜 6.5 \mu$ ，ほぼ中央に一次狭窄を持つ $\mathrm{V}$ 型 ( $\mathrm{F} \%=45 〜 46)$ で，さらにその一腕の端部近くに二 次狭窄が見られる。なおこのA染色体は，すでに前 期および前中期で, 多くの異質染色質をもつ異質染 色体であることが知られていて， $\mathrm{H}_{1}$ で示されてお り (辰野・小野 $\left.{ }^{7}\right)$, しかもその異質染色質の量と分 布が此雄の間で異なるので, 構造的性染色体X打よ びYとされている(辰野・瀬川1) . すなわち両染色
体の短腕はともに全部が 異質染色質で区別がない が，長腕の方に差があり，Yには基部と端部に，X に注端部のみに見られ基部には認められないとし て両染色体を区別している。しかし，筆者の詳細な 観察の結果では, 両染色体の長腕の基部には異質染 色質が認められ，ただその量がXよりYの方がやや 多い点で区別される $(\mathrm{X}: 0.5 \mu, \mathrm{Y}: 1.7 \mu)$ (Figs. $2,5,17,20,7$ ).
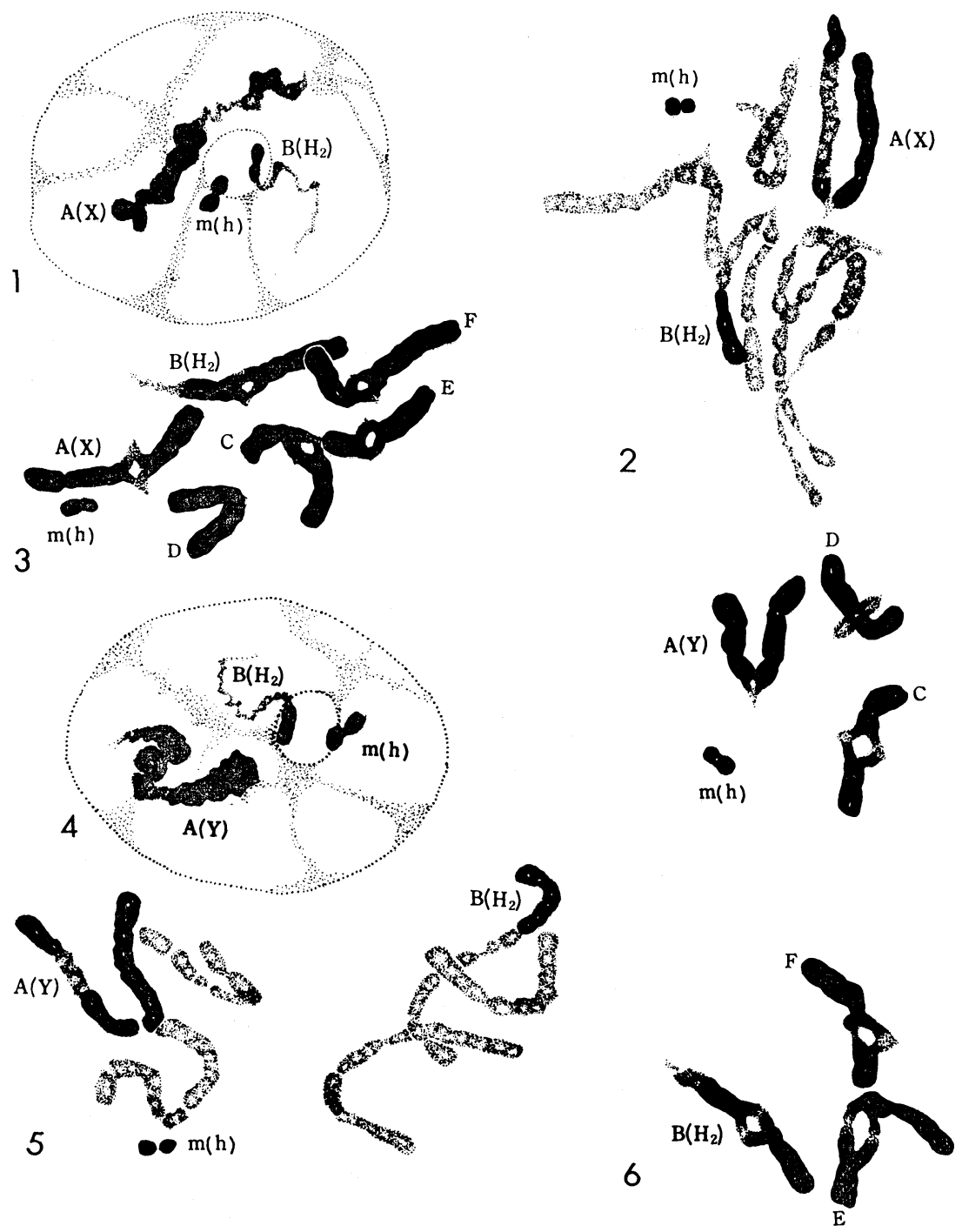

Figs. 1 6. Chromosomes and heteropycnosis of Mnium maximowiczii. (1 3) 우 and $(4 \sim 6)$ gametophytes. 1, 4, interphase; 2, 5, prometaphase ; 3, 6, metaphase. $\times 4000$. 
$\mathrm{B}$ 染色体 $\left(\mathrm{H}_{2}\right)$ は，さきに雌怢で報告されたごと く(辰野・小野7) $)$, 中期ではその短腕の端部の異質 染色質が negative heteropycnosisをして, 染ま らないので, 短腕が著しく短く一見 J 型染色体に見 えるが $(\mathrm{F} \%=33 \sim 34)$, 前中期では，この異質染色 部が逆に濃染して明らかになるので，この部をあわ せて測定すると，この染色体は本来 V 型である $(\mathrm{F} \%=45 \sim 47)$ (Table 1). なお, 雄株のB染色体 は雌株のそれと，長さおよび $\mathrm{F} \%$ において差が認 められない. C〜 m 染色体もまた雌雄の間で同長同

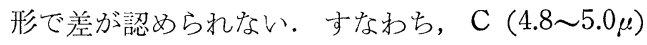
と D染色体 $(4.0 \mu)$ 法狭窄を中央に持つ $\mathrm{V}$ 型 $(\mathrm{F} \%=$

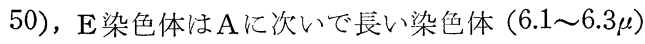
であるが， $\mathrm{F} \%=34 \sim 35$ で $\mathrm{F}$ 染色体（4.1〜4.7 $\mu$ ， $\mathrm{F} \%=28 \sim 32)$ と共に J 型である. $\mathrm{m}$ 染色体は此雄 核板中最小で $(1.1 \mu)$, 狭窄をほぼ中央に持つV型で ある $(\mathrm{F} \%=45)$. なおこの $\mathrm{m}$ は前期打よび前中期 で濃染し, 異質染色質からなるので $\mathrm{h}$ で示される.

さきに本種の雌株で指摘したごとく（辰野・小 野7), 中間期の核では, $\mathrm{H}_{1}, \mathrm{H}_{2}$ およびhの一腕の 異質染色質は仁中に入って小仁安作っている．これ は雄株でも同様である (Figs. 1, 4, 16, 19).

よって, 本種の核型は次のように示される。

$$
\left\{\begin{aligned}
\text { 오 } \mathrm{K}(\mathrm{n})=7= & \mathrm{V}\left(\mathrm{H}_{1} \mathrm{X}\right)+\mathrm{V}\left(\mathrm{H}_{2}\right)^{n h} \\
& +2 \mathrm{v}+\mathrm{J}+\mathrm{j}+\mathrm{m}(\mathrm{h}) \\
\mathrm{o} \mathrm{K}(\mathrm{n})=7= & \mathrm{V}\left(\mathrm{H}_{1} \mathrm{Y}\right)+\mathrm{V}\left(\mathrm{H}_{2}\right)^{n h} \\
& +2 \mathrm{v}+\mathrm{J}+\mathrm{j}+\mathrm{m}(\mathrm{h})
\end{aligned}\right.
$$

\section{ナガバチョウチンゴケ (Mnium japonicum)}

本種は広島県山県郡三段峡産のもので観察した. 本種の染色体数注雌雄とも $\mathrm{n}=7$ (Figs. 9, 11) で,
さきにのべた辰野・小野7)の結果と同様である.中 期核板に打ける染色体の形態は，さきにのべたツル チョウチンゴケのそれとほとんど同じであり, 雌雄 の間に相違が認められない.

本種では，まだ性染色体の報告はなかったが，筆 者の観察では, 本種でも $\mathrm{A}$ 染色体が, 構造的性染色 体XおよびYである。両染色体は中期核板では，と

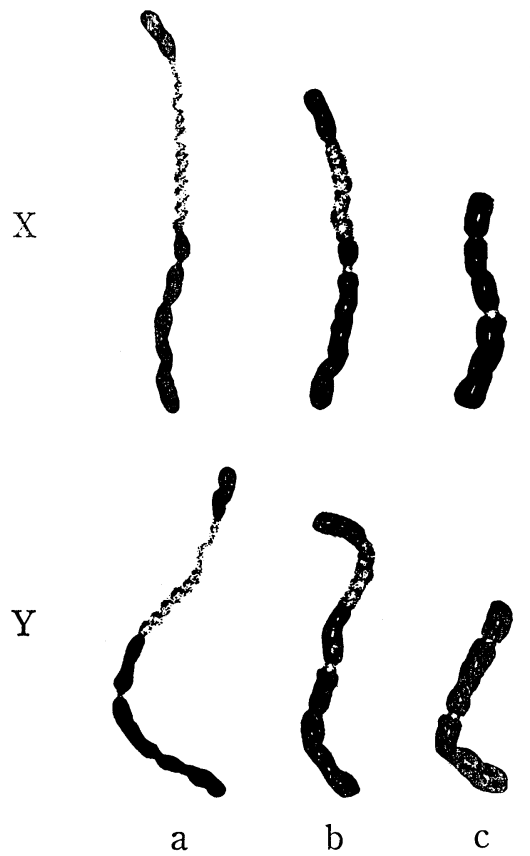

Fig. 7. Structural sex-chromosomes $(\mathrm{X}, \mathrm{Y})$ from prophase to metaphase of Mnium maximowiczii. $a$, prophase; $b$, prometaphase; $c$, metaphase. $\times 4000$.

Table 1. Measurements of somatic chromosomes of Mninm maximowiczii.

\begin{tabular}{|c|c|c|c|c|c|c|c|}
\hline \multicolumn{4}{|c|}{ 우 } & \multicolumn{4}{|c|}{$\hat{\delta}$} \\
\hline $\begin{array}{l}\text { Chromo- } \\
\text { some }\end{array}$ & Length $(\mu)$ & $\begin{array}{c}\text { Relative } \\
\text { length }\end{array}$ & $\begin{array}{c}\text { Form } \\
\%\end{array}$ & $\begin{array}{l}\text { Chromo- } \\
\text { some }\end{array}$ & Length $(\mu)$ & $\begin{array}{l}\text { Relative } \\
\text { length }\end{array}$ & $\underset{\%}{\text { Form }}$ \\
\hline$A(X)$ & $2.9+3.5=6.4$ & 19.8 & 45 & $A(Y)$ & $3.0+3.5=6.5$ & 20.0 & 46 \\
\hline $\mathrm{B}$ & $1.8+3.6=5.4$ & 16.6 & $33(45)^{*}$ & $B$ & $1.7+3.3=5.0$ & 15.4 & $34(47) *$ \\
\hline $\mathrm{C}$ & $2.5+2.5=5.0$ & 15.4 & 50 & $\mathrm{C}$ & $2.4+2.4=4.8$ & 14.8 & 50 \\
\hline $\mathrm{D}$ & $2.0+2.0=4.0$ & 12.4 & 50 & $\mathrm{D}$ & $2.0+2.0=4.0$ & 12.3 & 50 \\
\hline $\mathrm{E}$ & $2.1+4.0=6.1$ & 18.5 & 34 & $\mathrm{E}$ & $2.3+4.0=6.3$ & 19.4 & 35 \\
\hline $\mathrm{F}$ & $1.3+2.8=4.1$ & 12.7 & 32 & $\mathrm{~F}$ & $1.3+3.4=4.7$ & 14.1 & 28 \\
\hline $\mathrm{m}$ & $0.5+0.6=1.1$ & 3.3 & $45(45)^{*}$ & $\mathrm{~m}$ & $0.5+0.6=1.1$ & 3.3 & $45(45)^{*}$ \\
\hline
\end{tabular}

( )*: prometaphase. 
もにほぼ中央に一次狭窄, 長腕の端に二次狭窄を持 ち，区別できないが，前期および前中期で，異質染 色質の量と分布をたがいに 異にする 構造的性染色 体である. その異質染色質の量と分布の相違はツル チョウチンゴケのX および Y の場合とほとえど同 じである (Figs. 8, 10, 22, 23). すなわち, 両染色 体は短腕全部と長腕の端部と基部に異質染色質を 持つが, 長腕の基部のそれは量的に $\mathrm{Y} の$ 方がXより 多い $(\mathrm{X}: 0.6 \mu, \mathrm{Y}: 1.9 \mu)$.

B染色体は，本種でも短腕端が中期で negative heteropycnosis を示すので $\mathrm{H}_{2}$ であり，核板中最 小の $\mathrm{m}$ は $\mathrm{h}$ である.

此雄の中間期核板では， $\mathrm{X}$ または $\mathrm{Y}, \mathrm{H}_{2}, \mathrm{~h}$ の 異常凝絔が見られ， $\mathrm{H}_{2}$ の異質染色質， $\mathrm{h}$ の一腕の
異質染色質汇仁の中に入り，小仁を形成する。

よって, 本種の核型はッルチョウチンゴケと同じ く次のとおりである。

$$
\left\{\begin{aligned}
\text { ㅇ } \mathrm{K}(\mathrm{n})=7= & \mathrm{V}\left(\mathrm{H}_{1} \mathrm{X}\right)+\mathrm{V}\left(\mathrm{H}_{2}\right)^{n h} \\
& +2 \mathrm{v}+\mathrm{J}+\mathrm{j}+\mathrm{m}(\mathrm{h}) \\
\hat{\mathrm{O}} \mathrm{K}(\mathrm{n})=7= & \mathrm{V}\left(\mathrm{H}_{1} \mathrm{Y}\right)+\mathrm{V}\left(\mathrm{H}_{2}\right)^{n h} \\
& +2 \mathrm{v}+\mathrm{J}+\mathrm{j}+\mathrm{m}(\mathrm{h})
\end{aligned}\right.
$$

\section{コツボゴケ (Mnium cuspidatum var.}

\section{trichomanes)}

本種は広島市付近産のもので観察した。

本種の染色体数は雌雄とも $\mathrm{n}=7$ (Figs. 13, 15) で, 辰野9)の結果と一致する. 本種の此雄の中期核 板における染色体の形態は,さきにのべた 2 種とほ
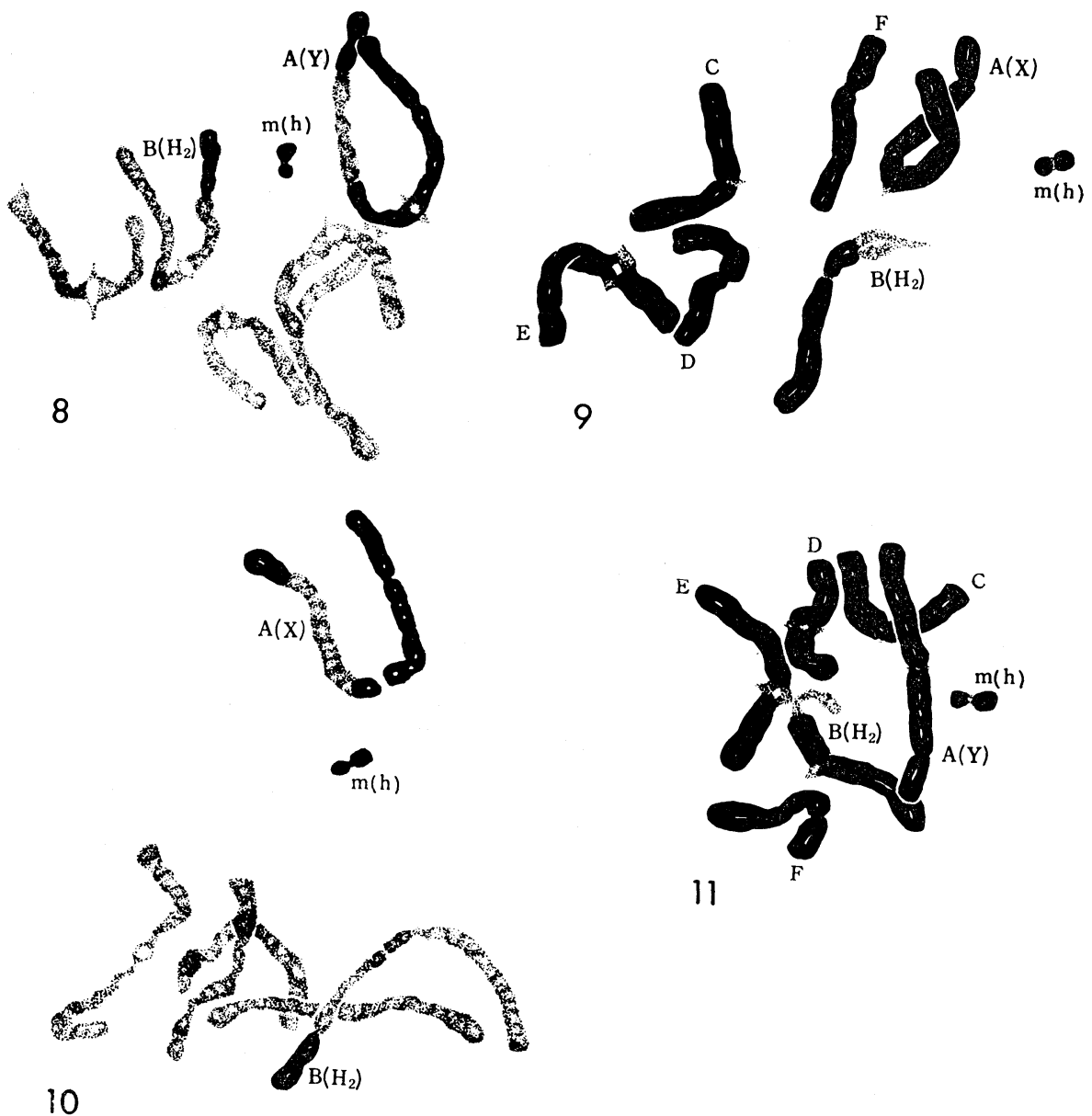

igs. 8 11. Chromosomes and heteropycnosis of Mnium japonicum. (8〜9) 우 and $(10 \sim 11)$ o gametophytes. 8,10 , prometaphase; 9,11 , metaphase. $\times 4000$. 
とえど同様であって, 此雄の間に区別は認められな い.しかし本種でもまた，此雄の核板中最長の $\mathrm{A}$ 染 色体は構造的性染色体であることが発見された。そ の $\mathrm{X}$ と $\mathrm{Y}$ との構造的差違はさきにのべた 2 種の場 合と同様である.すなわち，Yの長腕の基部の異質 染色質の量はXのそ机にくらべてやや多い (X: $0.8 \mu, \mathrm{Y}: 1.9 \mu$ ) (Figs. 12, 14).

本種でも B 染色体は短腕端が 中期で negative heteropycnosis 定し $\mathrm{H}_{2}$ であり， $\mathrm{m}$ は $\mathrm{h}$ である. 中間期の核では， $\mathrm{H}_{2}$ の異質染色質と $\mathrm{h}$ の一腕の異 質染色質は小仁を作る。

本種の核型はさきにのベた 2 種と同様次のとお りである。

$$
\left\{\begin{aligned}
\text { 우 } \mathrm{K}(\mathrm{n})=7= & \mathrm{V}\left(\mathrm{H}_{1} \mathrm{X}\right)+\mathrm{V}\left(\mathrm{H}_{2}\right)^{n h} \\
& +2 \mathrm{v}+\mathrm{J}+\mathrm{j}+\mathrm{m}(\mathrm{h}) \\
\text { o } \mathrm{K}(\mathrm{n})=7= & \mathrm{V}\left(\mathrm{H}_{1} \mathrm{Y}\right)+\mathrm{V}\left(\mathrm{H}_{2}\right)^{n h} \\
& +2 \mathrm{v}+\mathrm{J}+\mathrm{j}+\mathrm{m}(\mathrm{h})
\end{aligned}\right.
$$
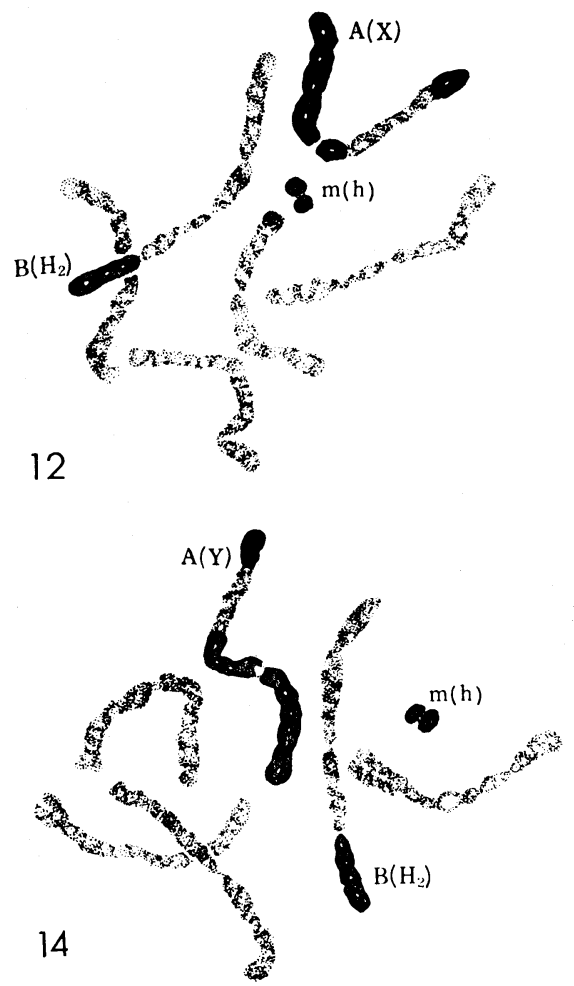

考察

さきに辰野・瀬川1) はチョウチンゴケ科のツル チョウチンゴケで, 初めて構造的性染色体を報告し た。それは雌雄の性染色体XYが，中期核板では大 きさおよび形態の差が見られないが，前期，前中期 の異質染色質の量と分布でたがいに相違する新し い型の性染色体であった. 筆者は本研究で, このッ ルチョウチンゴケの構造的性染色体を詳細に 再観 察するとともに, 分類学上これと同一 section に属 するチョウチンゴケ科の 2 種, ナガバチョウチンゴ ケとコツボゴケでも同様な構造的性染色体を発見 した。すなわち，これら 3 種の構造的性染色体では， $\mathrm{X}$ と $\mathrm{Y}$ はともに短腕は全部, 長腕は端部と基部が異 質染色質だが，長腕の基部の異質染色質の量はYの 方がXより多い.

瀬川 ${ }^{3-5)}$ は苔類の構造的性染色体を異質染色質の

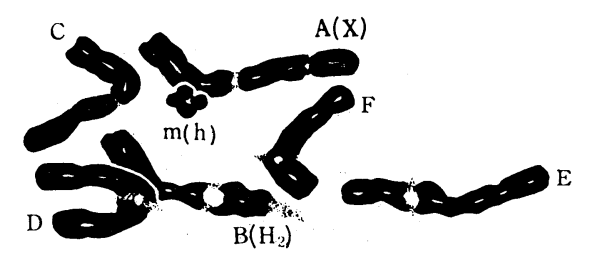

13

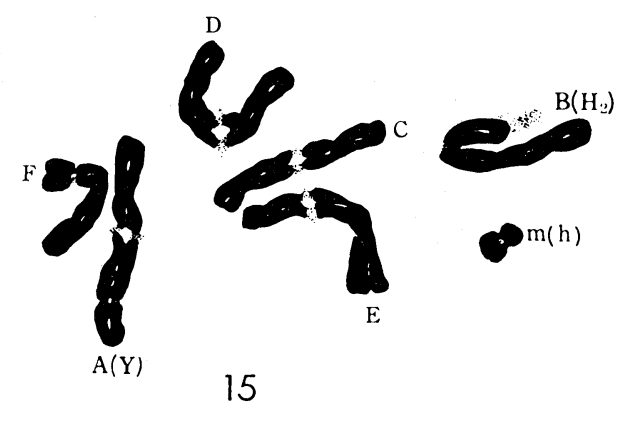

Figs. $12 \sim 15$. Chromosomes and heteropycnosis of Mnium cuspidatum var. trichomanes. $(12 \sim 13)$ 오 and $(14 \sim 15)$ $\delta$ gametophytes. 12, 14, prometaphase ; 13, 15, metaphase. $\times 4000$. 


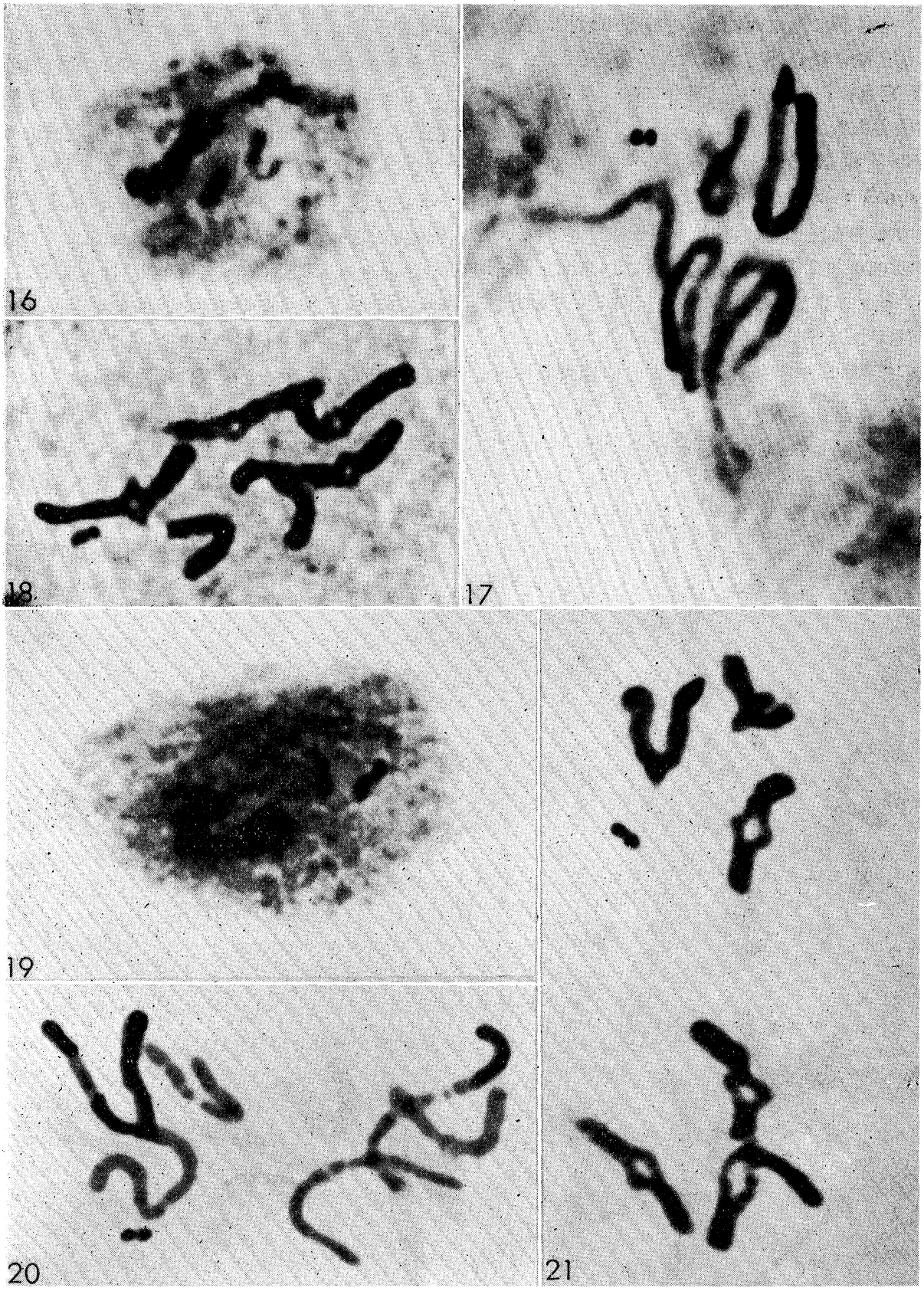

Figs. 16 21. Photomicrographs of the mitotic chromosomes in gametophytes of Mnium maximowiczii. (16 18) ㅇ gametophytes, $\mathrm{n}=7$. 16, interphase; 17 , prometaphase; 18, metaphase. $(19 \sim 21)$ $\delta$ gametophytes, $n=7$. 19, interphase; 20, prometaphase; 21 , metaphase. $\times 4000$. 


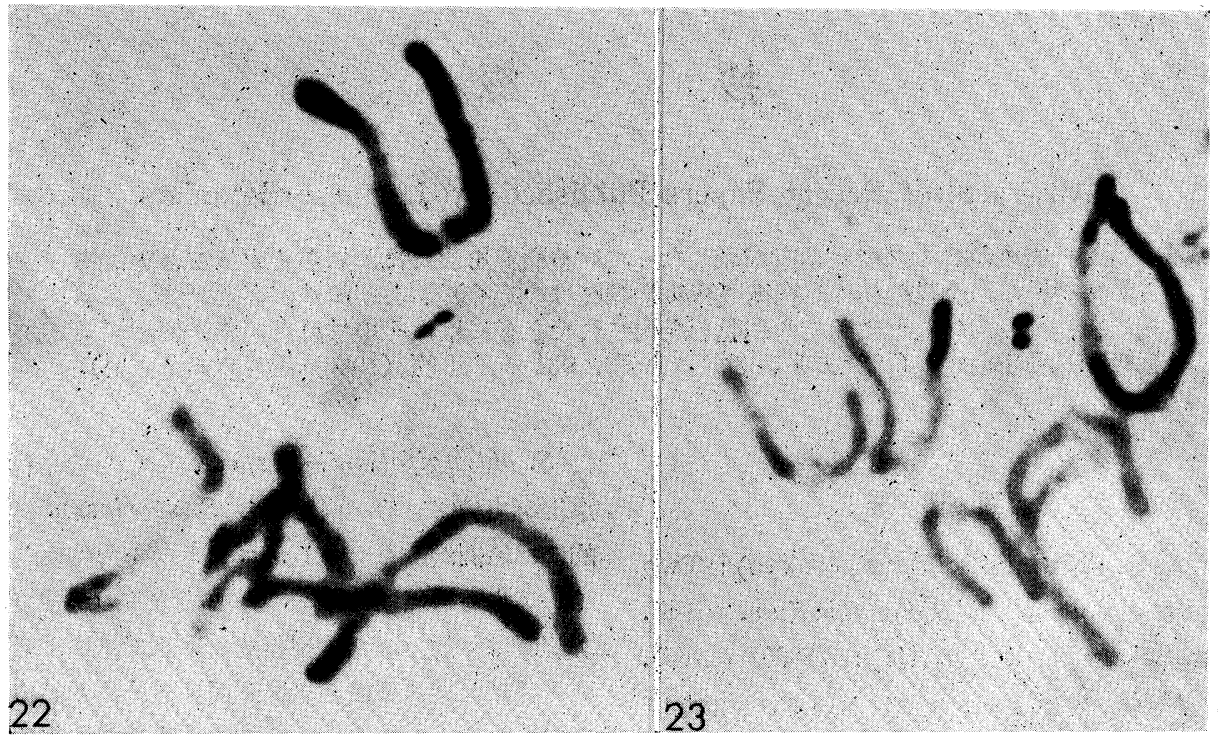

Figs. 22, 23. Photomicrographs of the mitotic prometaphase chromosomes in gametophytes of Mnium japonicum. 22, 우 gametophyte, $\mathrm{n}=7 ; 23$, 今 gametophyte, $\mathrm{n}=7 . \quad \times 4000$.

分布,すなわち染色体の内部構造の状態から Makinoa, Trichocolea, Bazzania, Plagiochila, Porel$l a$ の 5 型にわけているが, 筆者の観察したチョウチ ンゴケ属の 3 種の構造的性染色体は, これら 5 型の どれにも属さない新型である.しかもこれら 3 種は 同一 section に属する種であるから同一型の構造 的性染色体を持つものと考えられる.

終りに臨み, この研究は広島大学教授辰野誠次博 士の指導のもとにおこなわれたものであり, 本研究 で用いた材料は同大学の安藤久次博士に種の同定 をしていただいた。ここに両先生に心から感謝の意 を表します。

\section{摘 要}

1. 日本産チョウチンゴケ科の䧳雄異株の 3 種の
核学的研究, 特に構造的性染色体の観察をおこなっ た.

2. ナガバチョウチンゴケ，コツボゴケに構造的 性染色体を発見した。

3. ツルチョウチンゴケ, ナガバチョウチンゴケ およびさッボゴケの構造的性染色体は, いずれも此 雄の核板中最大の異質染色体 $\left(\mathrm{H}_{1}\right)$ で, 体細胞分裂 の前期および前中期で $\mathrm{Y}$ は Xより多くの異質染色 質を持つ.

4. 観察された 3 種の核型はいずれも次のようで ある。

$$
\left\{\begin{aligned}
\text { 오 } \mathrm{K}(\mathrm{n})=7= & \mathrm{V}\left(\mathrm{H}_{1} \mathrm{X}\right)+\mathrm{V}\left(\mathrm{H}_{2}\right)^{n h} \\
& +2 \mathrm{v}+\mathrm{J}+\mathrm{j}+\mathrm{m}(\mathrm{h}) \\
\text { \& } \mathrm{K}(\mathrm{n})=7= & \mathrm{V}\left(\mathrm{H}_{1} \mathrm{Y}\right)+\mathrm{V}\left(\mathrm{H}_{2}\right)^{n h} \\
& +2 \mathrm{v}+\mathrm{J}+\mathrm{j}+\mathrm{m}(\mathrm{h})
\end{aligned}\right.
$$

\section{文献}

1) Tatuno, S., und Segawa, M., J. Sci. Hiroshima Univ. B2 $7: 1$ (1955). 2) Segawa, M., Jap. J. Genet., $32: 197$ (1957).

3) , J. Sci. Hiroshima Univ. B2 10 : 69 (1965).

4) ibid. $10: 81$ (1965).
5) - ibid. 10:149 (1965).

6) Yano, K., Memo. Takata Branch, Fac. Educ. Niigata Univ. 1 : 85 (1957). 7) Tatuno, S., und Ono, K., J. Hattori Bot. Lab. 29: 79 (1966). 8) Shimotomai, N., und Koyama, Y., J. Sci. Hiroshima Univ. B2 1: 95 (1932). 9) Tatuno, S., La Kromosoma $8: 305$ (1951). 10) Tatuno, S., und Yano, K., Cytologia 18: 36 (1953). 